$1-27-2012$

\title{
What Type Of Framing Message Is More Appropriate With Nine- Ending Pricing?
}

Jungsil Choi

Cleveland State University, j.choi59@csuohio.edu

Kiljae Lee

University of Kansas

Yong-Yeon Ji

Towson University

Follow this and additional works at: https://engagedscholarship.csuohio.edu/bus_facpub

Part of the Advertising and Promotion Management Commons, and the Marketing Commons How does access to this work benefit you? Let us know!

Publisher's Statement

The final publication is available at Springer via http://dx.doi.org/10.1007/s11002-012-9164-7

Original Published Citation

Choi, J., Lee, K., Ji, Y. (2012). What type of framing message is more appropriate with nine-ending pricing? Marketing Letters, 23(3), 603-314. doi:10.1007/s11002-012-9164-7

This Article is brought to you for free and open access by the Monte Ahuja College of Business at EngagedScholarship@CSU. It has been accepted for inclusion in Business Faculty Publications by an authorized administrator of EngagedScholarship@CSU. For more information, please contact library.es@csuohio.edu. 


\title{
What type of framing message is more appropriate with nine-ending pricing?
}

\author{
Jungsil Choi $\cdot$ Kiljae Lee $\cdot$ Yong-Yeon Ji
}

\begin{abstract}
While the effect of nine-ending prices on purchases has been well documented, studies that examine the impact of this pricing technique in the context of advertisements are rare. This paper examines the joint effect of the pricing technique and message frames on the advertisement efficacy. Since a nine-ending price is compatible with gain-framed messages due to its gain image, we propose that nineending pricing strengthens the effectiveness of gain-framed messages (versus lossframed messages) on the overall advertisement efficacy. The results of two experiments provide support for this hypothesis.
\end{abstract}

Keywords Nine-ending prices - Gain-framed messages - Loss-framed messages · Advertisement $\cdot$ Regulatory fit

\section{Introduction}

People are sensitive to tiny differences in price, such that a penny reduction reflected in a nine-ending lowers the perception of a price, often, leading to a substantial increase in sales (Kalyanam and Shively 1998; Schindler and Kibarian 1996). This appears to be largely due to the left-digit effect: the underestimated perception that

J. Choi $(\square)$

Department of Marketing, School of Business, University of Kansus, 1300 Sunnyside Ave, Lawrence,

KS 66045, USA

c-mail: jungsilchoi@gmail.com

K. Lee

Department of Accounting and Information Systems, School of Business, University of Kansas, 1300 Sunnyside Ave, Lawrence, KS 66045, USA

Y.-Y. Ii

Department of Management, College of Business and Economics, Towson University, 8000 York Rd, Towson, MD 21252, USA 
stems from a unit reduction in the leftmost digit when a nine-ending (compared to a round-ending) price is used (Thomas and Morwitz 2005). In this account, the leftdigit effect is not a result from a quantitative advantage of a one-cent drop but from a perceptional distortion that occurs during the conversion of numerical symbols to mental magnitudes. Because this conversion typically follows the left-to-right processing (Thomas and Morwitz 2005) or truncation strategy (Schindler and Kirby 1997), the resulting magnitude perception is distorted toward the leftmost digit. For instance, while $\$ 29.99$ compared with $\$ 30.00$ makes a significant impact on purchases, $\$ 24.31$ compared with $\$ 24.32$ has a negligible impact on consumer decision-making although both sets of pricing have an equivalent difference. This view is consistent with a consumer's tendency to ignore a price's rightmost digit(s). Price recall tests demonstrate that people make more errors when the price of the purchased products is nine-ending rather than round-ending because of the lack of attention paid to the rightmost digit (Gueguen and Legoherel 2004). This overemphasis of the leftmost digit, along with the underemphasis of the rightmost digit(s), leads to a substantial underestimation of the price offered with a nine-ending.

An alternative account is labeled the perceived gain effect: the gain perception emanating from a nine-ending price, which is perceived as a round-number amount with a small gain (Schindler and Kirby 1997). In this view, the just-above zero ending round number serves as a reference point in price evaluation because of its high availability (Kahneman and Tversky 1979) or accessibility (Fazio et al. 1982). This view relies on the prospect theory (Kahneman and Tversky 1979) to further argue that the perceived value from this small gain tends to be exaggerated because the value function is negatively accelerating (Schindler and Kirby 1997).

Moreover, some researchers report a second-order effect of nine-ending prices. They argue that a nine-ending price communicates a low price because the typical use in the market generates this image in people's minds. They refer to this impression as the price-image effect; with a nine-ending, the price suggests that it is lower than the competitors' and that it is a discount or sales price. People tend to develop such associations (Quigley Jr and Notarantonio 1992; Schindler and Kibarian 2001) because, in the market, a nine-ending price is used more often with a low-price appeal, such as a claimed price discount (Schindler 2006). Although the three different theoretical perspectives highlight different aspects of nine-ending prices, they appear to complement each other to understand fully the effects of nine-ending prices.

While the extant literature has paid substantial attention to the impact of nineending prices on purchase decisions (Manning and Sprott 2009; Schindler and Kibarian 1996) and its underpinning mechanism (Bizer and Schindler 2005; Thomas and Morwitz 2005), few studies have investigated its effectiveness in conjunction with other critical components of an advertisement. For instance, there is no research that investigates what type of message best fits with this price presentation technique.

Taking this into consideration, we examine the effect of different types of framed messages (gain vs. loss) on the relationship between a nine-ending price and the advertisement effectiveness. The current work draws on the regulatory focus theory (Higgins 2000) to examine the joint effect of a nine-ending price and message framing on advertisement efficacy. 


\section{Regulatory fit and gain vs. loss framed messages}

According to Higgins (1997), there are two self-regulatory processes (promotion focus and prevention focus) that operate to serve fundamentally distinctive human needs. These two regulatory processes differ not only in the needs to satisfy, but also in the goals to achieve and in the salient psychological situations of interest. When one is engaged in a promotion (vs. prevention)-focused process, s/he is motivated to satisfy her or his growth (vs. safety) needs, aspired to attain her or his ideal (vs. ought) self, and therefore, sensitive to the presence of gains (vs. losses). People experience a regulatory fit when their chosen means to pursue aligns with their regulatory orientation (Higgins 2000). The theory recognizes two alternative types of such means: eagerness means vs. vigilance means. An eagerness means focuses on obtaining positive outcomes through proactive exploration of gains, whereas, a vigilance means focuses on rejecting negative outcomes through careful avoidance of losses. Thus, there is a natural inclination for the fit between the choice of means and the regulatory focus.

People tend to confuse the favorable experience of the fit with the experience of evaluating a subsequently chosen object so that the assessment of the former is transferred to the assessment of the latter (Higgins et al. 2003). This source confusion takes place in evaluating not only objects but also any of the attributes that compose the persuasion context (the source, message, and advocated position) (Cesario et al. 2004). Hence, when a message fits with regulatory orientation, the feeling-right experience generated from this fit will be transferred to the assessment of the attributes of the message enhancing its persuasion. In addition, the fit facilitates one's attention to the information that contributes to achieve his or her goal. When a message fits with one's regulatory focus, the message is more likely to be perceived as personally relevant, to be attend to, and to be allocated greater memory (Higgins and Spiegel 2004). Importantly, the theory suggests that whether one adopts a promotion or prevention focus is a function of not only dispositional factors but also situational factors (Higgins 1997).

Regarding the message framing as a way of modifying one of the situational factors, Lee and Aaker (2004) extend the regulatory focus theory to a messageframing context. The authors propose that the fit between message frame and regulatory focus leads to the enhanced processing fluency, which in turn creates the feeling-right experience. They show that gain-framed tagline messages are more persuasive when the content of the message is promotion-focused highlighting gains, while loss-framed messages are more persuasive when the content is preventionfocused highlighting losses.

A gain (or loss)-framed message, however, is not an identical notion with a promotion (or prevention) focused message. Message framing research draws on prospect theory (Tversky and Kahneman 1981) which postulates that a factually equivalent message leads to different human response depending on whether it is framed in terms of potential gains or in terms of potential losses. Because of its distinctive theoretical foundation, there is some conceptual conflict in categorizing the nonloss-framed message. For instance, Lee and Aaker (2004) conceptualize that the gain-framed message involves a gain or nonloss and the loss-framed message involves a loss or nongain. While, in the regulatory focus theory, a promotion- 
focused message involves a gain or nongain and the prevention-focused message involves a loss or nonloss (Detweiler et al. 1999). Moreover, some other researchers (e.g., Ramanathan and Dhar 2010) refer to message framing when they contrast the gain vs. nonloss-framed messages, both of which, may be considered as gain-framed in Lee and Aaker's (2004) categorization.

Despite these subtle discordances, research converges in concluding that gain (vs. loss) framing fits better with a promotion (vs. prevention) focus (e.g., Detweiler et al. 1999; Lee and Aaker 2004; Ramanathan and Dhar 2010). Such convergence appears to be based on the theoretical linkage that regardless of the technical differences in operationalizing the gain/loss-frame, fundamentally, it is the gain (vs. loss) quality of the operationalized message that leads to the fit effect (Detweiler et al. 1999; Petty and Wegener 1991). This gain (vs. loss) quality directs the customer's mental perception of appropriate strategy to attain the goal either toward approaching positive outcomes or toward avoiding negative outcomes. This chosen means strategy facilitates the processing fluency when it matches with the regulatory focus of the message contents (Detweiler et al. 1999). Promotion (vs. prevention) concerns are more persuasive when conveyed with a gain (vs. loss) framed message because the idea is more naturally processed and conceptually fluent (Lee and Aaker 2004).

Building on the notion of the fit between message framing and a regulatory focus, Ramanathan and Dhar (2010) take note of the fit among multiple situational factors. They examine the positive effects of the fit among multiple cues as well as the fit between a cue and a regulatory focus on the sales promotion. They argue that a gain framed message ("Get $\$ \times$ off") entices more purchases when it is presented to the promotion focused subjects, as well as, when it is presented with other compatible cues (e.g., familiarity of brand) that also prime the promotion focus. A gain-fiamed message primes a promotion focus because it prompts one to consider a gain of $\$ \times$ or positive outcomes. On the other hand, a nonloss-framed as "Save $\$ x$ " induces more purchases when it is presented to the prevention focused subjects and when it is presented with other compatible cues that also prime a prevention focus. A loss framed message primes a prevention focus because it prompts one to consider the nonloss of $\$ \times$. For instance, attaching a limited-time message (e.g., "offer expires _") increases the effectiveness of a discount offering that primes a prevention focus ("Save $\$ \times$ ") because the time-limit message sensitizes customers to the imminent chance of losing the discount opportunity. On the other hand, the unlimited-time message better fits with a discount offering that primes a promotion focus ("Get $\$ \times$ off") because it allows the customers to attend more to the gain rather than to any risk of loss.

Further extending these observations about the compatibility between message type and situational factors, we reason that there will be a predictable fit between message type and the cues emanating from the nine-ending price. Specifically, if a nine-ending price signals the gain-effect (Schindler and Kirby 1997), this gain image attached to a round number will produce a better fit when it is presented with a gainframed message. Because the gain-framed message primes a promotion focus (Ramanathan and Dhar 2010) and because the activated promotion focus engenders sensitivity to the presence of gains (Higgins 1997), the gain image of a nine-ending price will be more readily accessible when it is paired with a gain-framed message than when paired with a loss-framed message. In a promotion-focused process, an 
eagerness means (rather than a vigilance means) that requires proactive exploration of a gain to maximize its occurrence, serves as a preferred strategy. Thus, a gain-framed message (rather than a loss-framed message) will better facilitate the conceptual fluency (Lee and Aaker 2004) in processing this gain cue and better facilitate the accessibility (Ramanathan and Dhar 2010) to this gain signal in evaluating the advertisement. In other words, the gain-framed message will better guide consumers to locate the gain image inherent to the nine-ending price by prompting the customers to ask "Where is the gain?" but not leading them to ask "Where is the loss?"

Taken together, we contend that a gain-framed message, rather than a loss-framed message, will be more effective when combined with a nine-ending price because such pairing facilitates a greater processing fluency that contributes to the feeling-right experience of regulatory fit. These heightened perceptions of fluency and the feeling-right experience will enhance the overall effectiveness of the advertisement. Hence, we posit:

H1: A gain-framed message will be more effective than a loss-framed message when used with nine-ending pricing in increasing overall advertisement efficacy measured by attitudes toward the advertisement (Study 1), attitudes toward the service (Study 1 and Study 2), and purchase likelihood (Study 1 and Study 2).

We conducted two studies to examine the hypothesis. In study 1, we used a print advertisement for a local fitness center because it contains pricing information and advertisement messages. We replicated the findings in a yellow page type of advertisement for a nationwide cable TV service provider in study 2 . In study 1 , we compared the outcome resulting from using a nine-ending price with the outcome from a round-ending price. In study 2 , we compared the outcome from a nine-ending price with the outcome from "no-price information."

\section{Study 1: Advertisement for a local fitness center membership service}

The purpose of study 1 is to investigate whether gain- and loss-framed messages affect the effectiveness of a nine-ending price differently. Because gain-framed messages prime an individual's promotion focus, we predict that the promotionfocused will more fluently locate and process the gain image of nine-ending prices. Thus, gain-framed messages will be more effective than loss-framed messages to enhance the advertisement efficacy when paired with a nine-ending price.

\subsection{Method}

\subsubsection{Stimuli}

We designed an advertisement for a local fitness center. We created four types of print advertisements for stimuli. All of the figures and contents were identical except price information and the main message on the head and the tagline messages [e.g., "Don't miss out on buying your 6 pack from us with $\$ 39 /$ mo (versus $\$ 40 /$ mo.)"; "Don't lose enjoying our new infiared saunas" for a loss-framed message and "Buy your 6 pack from us with $\$ 39 / \mathrm{mo}$ (versus $\$ 40 / \mathrm{mo}$.)"; "Enjoy our new infrared saunas" for gainframed messages]. To avoid potential confusion from a perceived difference in 
typicality, which may affect consumers' motivation to process an advertisement (Goodstein 1993), we examined if the difference in message type produced such typicality perceptions. Thirty students participated in the pretest. We did not find any difference in message typicality $(t(28)=1.39, p>0.17)$ between the gain- and lossframed messages. We also tested whether the gain- and loss-framed messages actually create the intended effects. Forty-five students in a midwest university participated in the pretest for partial course credit. We measured the subjects' impression about the messages on a four-item seven-point scale (i.e., the messages foctus on the benefits of getting the service at the price, the messages focus on the failure to take the benefits of getting the service at the price ${ }^{\circledR}$, the messages focus on gains, the messages focus on losses ${ }^{\mathbb{Q}} ; 1$, strongly disagree-7, strongly agree; $\alpha=0.73$ ), where the mark indicates reverse order of the scale. We found that the subjects perceived the gainframed messages more focused on benefits and gains than the loss-framed messages $(t(43)=2.14, p<0.05)$.

\subsubsection{Design and participants}

We used a 2 (price: nine-ending vs. round-ending) $\times 2$ (message type: gain-framed vs. loss-framed) between subjects design. Ninety-one college students participated in the study for course credit $(59$ men, mean age $=21)$.

\subsubsection{Procedure}

Participants were randomly assigned to one of the four conditions and asked to follow the instructions about the study. After looking at their own assigned advertisement, they were asked to answer the given questions to provide their feedback on the advertisement. We measured attitudes toward the service on a three-item seven-point scale (unfavorable/favorable, bad/good, not useful/very useful; $\alpha=0.80$ ) and purchase likelihood on a one-item nine-point scale. We also measured attitudes toward the advertisement on a four-item seven-point scale (unfavorable/favorable, unpleasant/pleasant, boring/interesting, and bad/good; $\alpha=0.86$ ). We measured attitudes toward the advertisement because the stimulus was created exclusively for the study, which was assumed not to be affected by the participants' previous familiarity with the advertisement. Nevertheless, we measured familiarity with the fitness club membership service named "Excel Fitness Center" because name familiarity could affect evaluation for the service, regardless of actual awareness. Finally, we measured purchase relevance on a four-item seven-point scale (i.e., important/unimportant, irrelevant/relevant, means nothing to me/means a lot to me, of concern to melof no concern to me; $\alpha=0.89$ ). We considered familiarity as a covariate to control any effects derived from a previous information level because the level of product/service information affects purchase intentions (Anderson and Jolson 1980). Further, we considered purchase relevance as a covariate since it affects a consumer's decision making (Ajzen et al. 1996).

\subsection{Results}

We found that two covariates-familiarity and purchase relevance-were significantly correlated with our dependent variables, but were not correlated with two independent 
variables. Following Keppel (1982), we included these two variables as covariates in the analyses. We used planned contrasts because our hypotheses claim that gainframed messages are more effective than loss-framed messages when the price is nine-ending but that these two messages are comparable when the price is roundending. We applied a Bonferroni correction and set the alpha for significance at 0.025 $(0.05 / 2=0.025)$ for dependent variables because we have two comparisons.

\subsubsection{Attitudes toward the ad}

Planned contrasts showed that the gain-framed messages were more effective in enlancing favorable attitudes toward the ad than the loss-framed messages at a nine-ending price ( $M_{\text {gain }}=5.28$ vs. $\left.M_{\text {loss }}=4.47, F(1,85)=7.60, p=0.007\right)$. However, there was no difference in effectiveness of the two messages at a round-ending price $\left(M_{\text {gain }}=5.17\right.$ vs. $\left.M_{\text {loss }}=4.82, F(1,85)=1.76, p=0.189\right)$. Both familiarity $(F(1,85)=$ $5.91, p=0.017)$ and purchase relevance $(F(1,85)=9.75, p=0.002)$ had positive impacts on attitudes toward the advertisement.

\subsubsection{Attitudes toward the service}

The results showed that the gain-framed messages were more effective than the lossframed messages for increasing favorable attitudes toward the service at a nineending price $\left(M_{\text {gain }}=5.91\right.$ vs. $\left.M_{\text {loss }}=4.99, F(1,85)=10.81, p=0.001\right)$. However, the effectiveness of the two messages were not significantly different under the roundending price condition $\left(M_{\text {gain }}=5.65\right.$ vs. $\left.M_{\text {loss }}=5.58, F(1,85)=0.073, p=0.79\right)$. Purchase relevance was found to have a positive impact on attitudes toward the service provider $(F(1,85)=10.05, p=0.002)$ but familiarity had little impact $(p=0.89)$.

\subsubsection{Purchase likelihood}

We found that the gain-framed messages were marginally more effective in leading to an increase of purchase likelihood than the loss framed messages at a nine-ending price $\left(M_{\text {guin }}=6.10\right.$ vs. $\left.M_{\text {loss }}=4.78, F(1,85)=5.00, p=0.028\right)$. However, the gain-framed messages were not more effective than the loss-framed messages when the advertised pricing was round ending $\left(M_{\text {gain }}=5.63\right.$ vs. $\left.M_{\text {loss }}=5.46, F(1,85)=0.11, p=0.744\right)$. Both familiarity $(F(1,85)=4.56, p=0.036)$ and purchase relevance $(F(1,85)=9.73$, $p=0.002$ ) affected purchase likelihood more favorably. The results demonstrated that there is a strong joint effect between a nine-ending price and gain-framed messages. These results support our hypothesis that when used with nine-ending pricing, gainframed messages are more effective than loss-framed messages in increasing overall advertisement efficacy.

\section{Study 2: Advertisement for DIRECTV}

The purpose of the second study is to replicate the previous study in a marketing environment at which point, adopting nine-ending price is so pervasive that the potential gain image of the nine-ending price may be diluted while a round-ending 
price may cause unexpected confounding. To this end, we take the cable TV service context because most of its providers adopt nine-ending pricing (see Appendix A for details). To rule out the potential confounding from the unfamiliar round ending, we did not use a round-ending price. Instead, the control group was exposed to a non nine-ending price message that naturally parallels the paired messages but without specific price information.

\subsection{Method}

\subsubsection{Stimuli}

We adopted the original yellow page advertisement for DIRECTV for a study and designed four types of advertisements for stimuli. All the figures and contents were identical except for the price information and the main advertisement message ["Call now, and you will get plenty of premium TV service at $\$ 29.99$ (vs. at special price)" for a gain-framed message and "Call now, or you will lose a chance to get plenty of premium TV service at $\$ 29.99$ (vs. at special price)" for a loss-framed message]. In the pretest where 34 college students participated, we did not find any difference in message typicality $(t(32)=0.61, p>0.54)$ between the two types of messages.

We also tested whether the gain- and loss-framed messages actually create the intended effects. Forty-three college students at a midwest university participated in a pretest for course credit. We measured message perception on the same scale utilized in study $1(\alpha=0.75)$. We found that the subjects perceived the gain-framed message as more focused on benefits and gains than the loss-framed message $(t(41)=2.09$, $p<0.05)$.

\subsubsection{Design and participants}

We used a 2 [price: nine-ending ( $\$ 29.99$ ) vs. no specific price information (special price)] $\times 2$ [message type: gain-framed vs. loss-framed] between-subjects design for the study. From a major midwest university, 114 business school students participated in the study for course credit ( 68 men, mean age $=21$ ).

\subsubsection{Procedture}

We followed the same procedure as used in study 1 . We measured attitudes toward the advertised service provider (DIRECTV) on a three-item seven-point scale ( $\alpha=$ 0.88 ) and purchase likelihood on a one-item nine-point scale. We measured familiarity with the cable TV service and purchase relevance on the same scale we used in study 1.

\subsection{Results}

We found that familiarity was correlated with the independent variable, pricing type at a one-tailed value of $p<0.05$, showing people reported greater familiarity with a nine-ending price. This result is consistent with our expectation; given that most cable TV service providers adopt nine-ending, the greater familiarity is natural. We also 
found that purchase relevance was correlated with a message type at a one-tailed value of $p<0.05$, showing that people reported greater purchase relevance when the message was gain-framed. Following Keppel (1982), we could not include these two variables as covariates in the analyses because they were correlated with the independent variables. We used planned contrasts to assess the hypothesis and applied a Bonferroni correction and set the same alpha $(0.025)$ for significance for the two dependent variables.

\subsubsection{Attitudes toward DIRECTV}

We found that the gain-framed message was more effective than the loss-framed message for enlancing favorable attitudes toward the cable TV service provider at a nine-ending price $\left(\$ 29.99 ; M_{\text {gain }}=5.58\right.$ vs. $\left.M_{\text {loss }}=5.06, t(110)=2.42, p=0.019\right)$. However, the effectiveness of the two messages was comparable when the ad did not provide specific pricing information $\left(M_{\mathrm{gain}}=4.69\right.$ vs. $M_{\text {loss }}=4.94, t(110)=-0.97$, $p=0.338$ ).

\subsubsection{Purchase likelihood}

Contrasts showed that, at a nine-ending price, the gain-framed message (vs. the lossframed message) significantly increased the purchase likelihood of the cable TV service $\left(M_{\text {gain }}=6.36\right.$ vs. $\left.M_{\text {loss }}=4.93, t(110)=2.39, p=0.021\right)$. However, without specific pricing information, the gain-framed message had little edge on enhancing purchase likelihood ( $M_{\mathrm{gain}}=4.76$ vs. $\left.M_{\text {loss }}=4.50, t(110)=0.46, p=0.648\right)$. The results were consistent with those of study 1, further supporting the hypothesis that, when used with nine-ending pricing, gain-framed messages are more effective in increasing overall advertisement efficacy.

\section{General discussion}

The results demonstrate that an appropriate match of message and pricing type enhances advertisement efficacy. In study 1 , we found that when combined with gain-framed messages (vs. loss-framed), nine-ending pricing induces higher attitudes toward the advertisement, attitudes toward the service, and purchase likelihood. In study 2 , we replicated the findings of study 1 in another advertisement context where nine-ending prices are the norm.

These results are consistent with our theoretical expectation that this joint effect is facilitated by the fit between the gain image of nine-ending prices and the promotion focus activated by the gain-framing of the message. Because a promotion focus favors an eagerness means, the gain-framed message encourages consumers' inclination toward a proactive exploration of the gain. Thus, the gain-framing of the message renders the gain image of a nine-ending price more conceptually fluent, producing a better fit and engendering better outcomes of the advertisement. With these results, we conclude that gain-framed messages (rather than loss-framed messages) contribute to a favorable advertisement outcome when paired with a nine-ending price because the gain- 
framed messages enhance conceptual fluency in processing the gain cue inherent to the nine-ending price.

One limitation of the current work is that it did not exhaustively compare the different magnitudes of the reported joint effects on the four different message-framing options (i.e., gain, nonloss, loss, nongain). Because the current research is based on the premise that the message framing effect essentially comes from the presence or absence of the gain (vs. loss) quality of the operationalized message (Detweiler et al. 1999), we expect consistent results, even if all four message framing (i.e., comparing nonloss vs. nongain) were separately observed. However, some researchers suggest each of these four message-framing options may entail different consequences (Higgins et al. 1994). Thus, with current results alone, we are unable to rule out the possibility that the reported joint effect may be systematically reduced if the equivalent messages are gain-framed by nonloss and loss-framed by a loss. Another limitation is associated with the semantic structure of "special price" used in study 2 . While it helped to avoid the potential confounding from using a round-ending price in a context where nineending prices are almost the norm, the wording could have conveyed a complicated cue that might have led our results beyond what is discussed here.

Despite these limitations, our findings may have a few important contributions. Although both regulatory focus and nine-ending pricing are well-established subjects in marketing literature, no study has considered the joint effect of the two concepts in predicting the effectiveness of advertisements. In this regard, our findings on the moderating role of pricing techniques in the relationship between message framing and the advertisement effectiveness represent a pioneering contribution to marketing literature. We expect various potential avenues to apply or build on the implication of the current research. By extending the variables of interest beyond pricing strategy toward a variety of situational factors that may alter or be influenced by customers' regulatory focus, future studies may further elaborate on better combinations to improve marketing communication efficacy (e.g., Pham and Avnet 2009; Ramanathan and Dhar 2010).

The findings also provide insights for marketing practitioners. This study offers a novel perspective that helps to select a better message frame to be paired with a pricing strategy. Further, this study implies that, in advertisements, presenting the specific price information may be more desirable for a productive marketing communication, unless there is a specific reason to veil such information. Though tested only in a printed advertising context, the implications of this research may generalize to the extent that take a broader form of advertisement media (e.g., online ad), as long as it carries a clear text message paired with a nine-ending price.

\section{Appendix A}

Table 1 Advertised prices of cable TV service providers

\begin{tabular}{ll}
\hline Cable TV service provider & Advertised price/mo. \\
\hline Time Warner & $\$ 29.99$ \\
Comcast Cable TV & $\$ 29$
\end{tabular}


Table 1 (continued)

Cable TV scrvice provider

Advertised price/mo.

DISH Network

$\$ 24.99, \$ 19.99$

Cox Digital Cable

$\$ 29.99$

DirecTV

$\$ 29.99$

\section{References}

Ajzen, I., Brown, T. C., \& Rosenthal, L. H. (1996). Information bias in contingent valuation: Effects of personal relcvance, quality of information, and motivational orientation. Journal of Environmental Economics and Management, 30, 43-57.

Anderson, R. E., \& Jolson, M. A. (1980). Technical wording in advertising: Implications for market segmentation. Jounal of Marketing. 44(1), 57-66.

Bizer, G. Y., \& Schindler, R. M. (2005). Direct evidence of ending-digit drop-off in price information processing. Psychology and Marketing. 22(10), 771-783.

Cesario, J., Grant, H., \& Higgins, E. T. (2004). Regulatory fit and persuasion: Transfer from "Fecling Right". Journal of Personality and Social Psychology: 86(3), 388-404.

Detweiler, J. B., Bedell, B. T., Salovey, P., Pronin, E., \& Rothman, A. J. (1999), Message framing and sunscreen usc: Gain-framed messages motivate beach-gocrs. Healh Psychology, 18(2), 189196.

Fazio, R. H., Chen, J., McDoncl, E. C., \& Sherman, S. J. (1982). Attitude accessibility, attitude-behavior consistency, and the strength of the object-evaluation association. Journal of Experimental Social Psychology, /8(4), 339-357.

Goodstein, R. C. (1993). Category-based applications and extensions in advertising: Motivating morc extensive ad processing. Joumal of Consumer Research, 20(1), 87-99.

Gueguen, N., \& Legoherel, P. (2004). Numerical encoding and odd-ending prices: The effect of a contrast in discount perception. European Journal of Marketing, 38(1/2), 194-208.

Higgins, E. T. (1997). Beyond pleasure and pain. American Psychologist, 52(12), 1280-1300.

Higgins, E. T. (2000). Making a good decision: Valuc from fit. American Psychologist, 55(11), 1217.

Higgins, E. T., \& Spicgel, S. (2004). Promotion and prevention strategics for self-regulation. Handbook of self-regulation: Research, theory; and applications. New York: Guilford Press. pp 171-187

Higgins, E. T., Roncy, C. J. R., Crowe, E., \& Hynes, C. (1994). Ideal versus ought predilections for approach and avoidane distinct self-regulatory systems. Journal of Personality and Social Psychology, $66(2), 276-286$.

Higgins, E. T., Idson, L. C., Freitas, A. L., Spiegel, S., \& Molden, D. C. (2003). Transfer of value from fit. Journal of Personality and Social Psychology, $84(6), 1140-1153$.

Kalncman, D., \& Tversky, A. (1979). Prospect theory: An analysis of decision under risk Econometrica, $47(2), 263-292$.

Kalyanam, K., \& Shively, T. S. (1998). Estimating irregular pricing effects: A stochastic spline regression approach. Joumal of Marketing Research, 35(1), 16-29.

Keppel, G. (1982). Design and analysis: A researcher; handbook (2nd ed.). Englewood Cliffs, N3: Prentice-Hall.

L.ec, A. Y., \& Aaker, J. L. (2004). Bringing the frame into focus: The influence of regulatory fit on processing flucncy and persuasion. Journal of Personality and Social Psychology, 6(2), 205-218.

Manning, K. C., \& Sprott, D. E. (2009). Price cndings, left-digit effects, and choicc. Journal of Consumer Research, 36(2), 328-335.

Petty, R. E., \& Wegener, D. T. (1991). Thought systems, argument quality, and persuasion. Adrances in social cognition, 4, 147-161.

Pham, M. T., \& Avnct, T. (2009). Contingent reliance on the affect heuristic as a function of regulatory focus. Organizational Behavior and Human Decision Processes, 108(2), 267-278.

Quigley, C. J. Jr., \& Notarantonio, E. M. (1992). An exploratory investigation of perceptions of odd and even pricing. Developnents in marketing science. In: V. L. Crittenden (Ed), Chestnut Hill, MA: Academy of Marketing Science 
Ramanathan, S., \& Dhar, S. K. (2010). The effect of sales promotions on the size and composition of the shopping baskct: Regulatory compatibility from framing and temporal testrictions. Journal of Marketing Research, 47(3), 542-552.

Schindler, R. M. (2006). The 99 price cnding as a signal of a low-price appeal. Journal of Retailing. 82(1), $71-77$.

Schindler, R. M., \& Kibarian, T. M. (1996). Increased consumer sales response though use of 99-ending prices. Journal of Retailing, 72(2), 187-199.

Schindler, R. M., \& Kibarian, T. M. (2001). Image communicated by the use of 99 endings in advertised prices. Joturtal of Advertising. 30(4), 95-99.

Schindler, R. M., \& Kirby, P. N. (1997). Patterns of rightmost digits used in advertised prices: implications for ninc-cnding effects. Joumal of Consumer Research, 24(2), 192-201.

Thomas, M., \& Morwitz, V. (2005). Penny wisc and pound foolish: The left-digit effect in price cognition. Journal of Consumer Research, 32(1), 54-64.

Tversky, A., \& Kalmeman, D. (1981). The framing of decisions and the psychology of choice. Science, $2 / 1$ (4481), 453 